\title{
O Cliente e o Design Estratégico: uma análise da percepção das organizações após a implementação das estratégias.
}

\author{
NASCIMENTO, Manoela; Mestre em Design Estratégico; Universidade do Vale do Rio dos Sinos \\ mfreitasn@gmail.com
}

\begin{abstract}
Palavras-Chave: Design Estratégico. Construção da Estratégia. Perspectiva do Cliente.
Resumo: O cenário econômico tem sofrido constantes transformações e exigido das organizações iniciativas que as mantenham diferenciadas de seus concorrentes. Nesse contexto, se vê surgir a oportunidade para que novas abordagens sejam adotadas pelas empresas, a fim de complementarem modelos de gestão já estabelecidos. Considerando que a prática do design se faz necessária àqueles que têm que lidar com decisões em um contexto turbulento e incerto, na medida em que permite que as organizações enfrentem o complexo cenário contemporâneo, torna-se possível refletir sobre sua contribuição para o desenvolvimento de estratégias organizacionais. Embora, se reconheça o design como um ativo estratégico de alto desempenho, ainda encontram-se poucos estudos no contexto brasileiro que apresentem elementos que destaquem sua importância em nível estratégico. Dessa forma, o presente estudo tem como objetivo analisar a percepção das empresas, após implementarem estratégias desenvolvidas sob perspectiva do design estratégico. Para alcançar tal propósito, realizou-se uma investigação de natureza exploratória, por meio de quatro entrevistas em profundidade com clientes de uma empresa de Tecnologia da Informação (TI), de Porto Alegre/RS. Com os resultados encontrados busca-se contribuir com estudos que pretendem compreender o papel do design como orientador de estratégias organizacionais, ampliando o foco em processos de construção da estratégia para uma perspectiva mais ampla, a qual engloba a percepção do cliente em relação às potencialidades do design do estratégico.
\end{abstract}

\section{Introdução}

O atual panorama econômico tem se mostrado altamente dinâmico, com constantes transformações que têm provocado as organizações a tomarem iniciativas que as mantenham no mercado de forma diferenciada e competitiva. Assim, se vê surgir a oportunidade para que novas práticas sejam complementadas aos modelos de gestão já estabelecidos. Nesse contexto, considera-se oportuno refletir sobre a contribuição do design para a construção, execução e tangibilização de estratégias organizacionais.

A visão estratégica do design tem muito a oferecer às empresas, quando levado a um nível estratégico. O termo "estratégico" relacionado ao design qualifica tal disciplina como uma área orientada às decisões empresariais, atuando não apenas nas práticas operacionais das organizações (CELASCHI e DESERTI, 2007). Segundo os autores, o design estratégico tem a capacidade de agregar valor às organizações, na medida em que assume o papel de projetar este valor. Complementando, Mauri (1996) esclarece que as organizações necessitam projetar uma oferta global, ou seja, é preciso projetar, coordenar e orientar todos os fatores imateriais, de relação, de serviço, de distribuição, de imagem e de comunicação com o mercado. Dessa forma, o design estratégico torna-se capaz de assumir o compromisso de unir as organizações e a sociedade, tendo necessariamente que admitir novas funções dentro das empresas (FRANZATO, 2010). 
Propondo uma visão holística, não focando suas capacidades somente em ofertas, mas em toda a cadeia de valor, Zurlo (2010) ao relacionar design e estratégia, esclarece que o design estratégico atua em contextos coletivos, suportando a ação estratégica devido à sua capacidade de gerar efeito de sentido entre todos os envolvidos, concretizando o resultado em sistemas de oferta e não em soluções pontuais. Ou seja, além de projetar produtos ou serviços, sua lógica processual compreende o desenvolvimento de estratégias que unem aspectos funcionais, valor simbólico e emocional, que buscam atender questões utilitárias, afetivas e socioculturais. Assim, o efeito de sentido, gerado pelo seu processo, apresenta um sistema de valores que vai além de questões técnicas. $O$ valor projetado pelo design estratégico carrega significados extrínsecos a um conjunto de elementos que transmitem mensagens e experiências que façam sentido a todos os indivíduos de um determinado contexto (CARDOSO, 2004).

Se tratando de uma disciplina centrada nas pessoas, sua prática estratégica consegue equilibrar o pensamento analítico da gestão com o pensamento exploratório do design (LOOCKWOOD, 2010). Desse modo, o design estratégico sendo orientador do processo de formulação da estratégia, pode contribuir com um olhar diferenciado para os recursos disponíveis nas organizações, bem como para suas ambições a longo prazo.

Desse modo, se vê crescer o número de empresas que têm recorrido às práticas do design como meio de gerarem competitividade e diferenciação aos seus negócios. Contudo, mesmo que se reconheça o design como um ativo estratégico de alto desempenho, ainda encontram-se dificuldades em compreender e medir seus resultados de forma isolada (ROE, 2013), bem como estudos no contexto brasileiro que apresentem elementos que destaquem a importância do design como norteador de estratégias organizacionais. Considerando estes pontos, se tem o seguinte questionamento: "Como as organizações atribuem seus resultados à perspectiva do design estratégico?"; o presente estudo tem como objetivo analisar a percepção das empresas em relação aos resultados obtidos, após implementarem estratégias orientadas pelo design.

A fim de alcançar tal propósito, realizou-se uma pesquisa qualitativa com quatro clientes de uma empresa de Tecnologia da Informação (TI), de Porto Alegre/RS. A empresa de TI, além de se dedicar ao desenvolvimento de softwares, oferece serviços fundamentados pela perspectiva do design estratégico, tais como: desenvolvimento de novas estratégias para produtos, serviços ou modelos de negócios dos seus clientes.

Com este artigo, pretende-se contribuir com estudos que buscam compreender o papel do design como orientador de estratégias organizacionais, ampliando a visão focada no processo de construção da estratégia para uma perspectiva mais ampla. Tal perspectiva considera que a investigação sobre o papel do design nos processos de construção de estratégias apresente elementos que apontem suas potencialidades nos resultados e vantagens competitivas alcançados pelas organizações.

Assim, este estudo está dividido em cinco seções. Primeiramente, apresenta-se uma revisão teórica sobre a perspectiva do design estratégico e a construção da estratégia no design. Em seguida, esclarece-se 
o método de pesquisa bem como coleta e análise dos dados. A seção seguinte corresponde aos resultados e discussões e, por fim, apresenta-se as principais conclusões desta investigação.

\section{A Perspectiva do Design Estratégico}

As organizações, diante da alta competitividade e intensa busca por soluções inovadoras, necessitam aliar seus conhecimentos a um posicionamento estratégico. Por ser uma prática centrada no desenvolvimento de ofertas a um olhar estratégico sobre a atividade projetual, a perspectiva do design torna-se capaz de atender um contexto dinâmico, global e de alta complexidade (MORAES, 2010). A relação entre design e estratégia se estabelece, na medida em que o design converge com questões de natureza complexa ou mal definida.

Nesse sentido, Cross (1982) esclarece que o designer não aceita, simplesmente, um problema de projeto, mas desenvolve toda a configuração desse problema, especulando as fronteiras que o cercam e trazendo para o projeto contribuições críticas. Assim, ele passa de executor a proponente de uma determinada visão, tendo como objetivo principal proporcionar valores e ferramentas às organizações, dando condições para que desenvolvam sua própria identidade, de maneira que influenciem e modifiquem o contexto no qual estão inseridas (MERONI, 2008).

Desse modo, entende-se que o processo de design objetiva aliar suas práticas à estratégia, propondo uma abordagem diferenciada dos demais processos de desenvolvimento de bens ou serviços. Sua lógica permite a articulação entre os diferentes pontos de contato que contemplam as ofertas, dentro e fora das organizações, destacando-se por considerar todos os atores de um determinado contexto. Freire (2014) descreve que sua ação projetual busca desenvolver soluções que englobam o ponto de vista das organizações, dos fornecedores, dos colaboradores e dos usuários em um único processo de coprodução de valor. Por isso, o design estratégico tem sido considerado, por muitos pesquisadores e profissionais um recurso indispensável para o desenvolvimento e o aprimoramento de estratégias empresariais (CELASCHI e FRANZATO, 2012).

Observa-se, que existem diferentes leituras sobre o propósito do design estratégico, contudo é possível identificar pontos recorrentes nas mais variadas definições, tais como: sua capacidade de habilitar um processo dialógico entre diferentes atores; sua dimensão situada (relacionada à operacionalidade dos objetivos das circunstâncias da ação); e, sua pretensão em atender diferentes necessidades, alcançando resultados de valor (ZURLO, 2010). São nesses três aspectos que o design estratégico assume o papel de projetar e agregar valor às empresas.

Cautela e Zurlo (2006) complementam, trazendo uma visão evolutiva do design dentro das organizações, a qual entende que o objetivo do design estratégico torna-se a projetação de produtos, serviços, comunicação e experiências, ampliando o seu foco de questões apenas estéticas e funcionais. Dessa forma, as organizações, por meio do design estratégico, podem criar vantagens competitivas desde a construção de estratégias e concepção de ideias até a finalização de um projeto. 
Entende-se que o seu processo permite articular elementos referentes à organização, ao seu público-alvo e ao contexto de consumo, figurando um sistema que ofereça uma experiência positiva em relação à oferta projetada. Considera-se assim, o design estratégico sob uma perspectiva processual, capaz de reunir habilidades e competências entre diferentes disciplinas, além de gerar aprendizado e efeito de sentido entre todos os envolvidos no contexto analisado.

Portanto, é através da transdisciplinaridade e do diálogo que o design estratégico busca integrar áreas distintas, dentro e fora da empresa, possibilitando assim, uma visão mais completa do todo e das partes. Ou seja, torna-se um articulador de diferentes frentes, envolvido no processo projetual de toda a cadeia de valor que as organizações desenvolvem para tangibilizarem suas estratégias.

\section{A Construção da Estratégia no Design}

No contexto das organizações, por estratégia entende-se a maneira como uma empresa se apresenta ao mercado (PORTER, 1996). Para o autor trata-se de uma escolha da organização por executar uma ou mais atividades de forma diferenciada dos seus concorrentes, sendo o mais importante a interrelação entre essas atividades. Tais ações devem ser executadas de forma única a produzir valor percebido, para então formar a essência da estratégia.

Considerando o campo do design, Mauri (1996) esclarece que, diante da complexidade do cenário contemporâneo, a estratégia não se trata de predeterminar ou planificar, mas sim de executar uma série contínua e indefinida de aproximações, composições, decomposições e recomposições; acompanhando de forma simultânea novas informações e acontecimentos. Para o autor, é importante considerar o paradoxo de projetar a estratégia. Isto é, a organização por estar exposta a tensões contraditórias e imprevisíveis, necessita se adaptar e se reorganizar continuamente, agindo de acordo com as informações relativas à estratégia.

Dessa forma, o design estratégico apropriando-se do meio organizacional como espaço de atuação, assume o papel de articulador da interação entre uma série de fatores e indivíduos que contribuem para a evolução das estratégias organizacionais. Zurlo (2010) comenta que a projetação de valor por meio do design tem como objetivo o conjunto integrado de produto, serviço e comunicação com o qual uma organização se coloca no mercado, se apresenta na sociedade e dá forma à própria estratégia.

Por ser uma disciplina interpretativa que busca compreender as relações simbólicas das ofertas com os desejos dos usuários e das organizações, o autor atribui a competência do design estratégico às suas capacidades funcionais de ver, prever e fazer ver. Para desempenhar sua ação estratégica, é necessário que o design se proponha a compreender a realidade e o contexto nos quais as organizações estão inseridas, através do metaprojeto, buscando uma visão crítica-reflexiva do problema de projeto.

Segundo Celaschi e Franzato (2012) a prática metaprojetual propõe a evolução de uma reflexão acerca do projeto em desenvolvimento, vinculada ao contexto que o originou e ao cenário para o qual é 
destinado. Para os autores, esta abordagem provoca o aprofundamento do problema e dos objetivos do projeto, para a então definição do melhor processo para a busca de uma solução adequada. Dessa forma, compreende-se que a ação metaprojetual torna-se apropriada em processos empresariais que buscam repensar a atuação de uma organização e a definir suas estratégias futuras. Considera-se assim, o metaprojeto como uma atividade transdisciplinar fundamentada na pesquisa e tencionada para dentro do projeto ao longo das diferentes etapas do processo de design.

Sua lógica indica que são fundamentais as fases iniciais de busca e análise do problema para que, posteriormente, sejam pesquisadas novas soluções. Por meio de uma abordagem sistêmica, o design estratégico passa a atuar livremente, aproximando-se de diferentes disciplinas, fazendo com que a estratégia seja proporcionada por meio do metaprojeto.

Como consequência, o design estratégico acaba se beneficiando da criatividade social na construção de cenários futuros possíveis, que podem ser gerenciados pelos diferentes atores, se o processo de projeto for compartilhado e participativo (MERONI, 2008). Para a autora, a abordagem e o processo do design estratégico permite que diferentes disciplinas colaborem para a resolução do problema de projeto.

Portanto, a partir da associação do design com diferentes áreas de conhecimento, resultando na criação de valor, formas, experiências, processos e sistemas, é que se desenvolve a estratégia. Dessa forma, o design estratégico, segundo Celaschi e Deserti (2007), assume o papel de design driven, sendo corresponsável pela conexão organização-contexto. Assim, por meio do metaprojeto, o design atua ao longo de toda a cadeia de valor, desde a idealização, programação, realização, comunicação até a distribuição de ofertas e serviços de pós-venda, com o objetivo de agregar valor às empresas, aos consumidores, ao mercado e a sociedade como um todo.

A fim de complementar os conceitos e a reflexão sobre o tema em questão, apresenta-se uma análise sobre a percepção das organizações após a implementação de estratégias desenvolvidas por meio do design estratégico.

\section{Método}

O método deste estudo, de caráter exploratório/qualitativo, justifica-se pelo objetivo desta pesquisa, que busca compreender como as organizações atribuem seus resultados à perspectiva do design estratégico, bem como de que forma o percebem após a implementação de suas estratégias. Dessa forma, realizou-se 4 entrevistas em profundidade, com clientes de uma empresa de Tecnologia da Informação, de Porto Alegre/RS, que além de desenvolvimento de softwares, presta serviços de design estratégico.

Assim, como critério de participação na investigação, todos os quatro clientes analisados deveriam ter contratado o serviço de design para o desenvolvimento de estratégia para suas ofertas ou modelos de negócio. Como o objetivo está relacionado à análise da percepção dos clientes em relação às estratégias 
desenvolvidas sob a perspectiva do design estratégico, foi fundamental este grupo ter em comum o mesmo processo de trabalho, bem como os atores envolvidos. A Figura 1 esclarece as etapas do projeto e o perfil dos participantes:

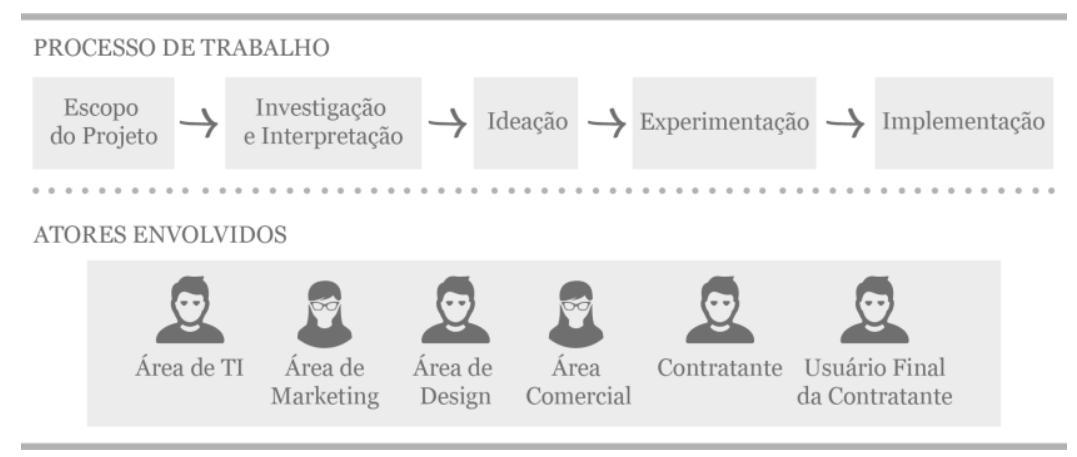

Figura 1: Critério para definição da amostra. Fonte: desenvolvido pela autora.

Verifica-se que o processo de trabalho realizado com as empresas entrevistadas se estabeleceu em cinco etapas chaves do processo de design, sendo elas: escopo do projeto, na qual se conhece a demanda inicial do cliente e se obtém informações concretas sobre o contexto a ser trabalhado; investigação e interpretação, onde se busca ampliar os conhecimentos sobre a questão explorada, permitindo a identificação de novas oportunidades; ideação, fase em que acontece a geração de ideias de fato; experimentação, momento em que as ideias propostas são prototipadas e colocadas em experimentação com usuários; e implementação, etapa em que a empresa lança no mercado o modelo ideal das proposições desenvolvidas ao longo do processo. Em relação aos atores, os projetos dos quatro clientes investigados envolveram profissionais da área de TI, Marketing, Design e Comercial da empresa contratada, além de profissionais da empresa contratante e seus usuários finais.

Os entrevistados representam as áreas gerenciais de suas empresas, sendo elas integrantes do setor terciário (hoteleiro e financeiro), e responsáveis pela contratação dos serviços prestados pela empresa de TI. As ocupações dos participantes são: gerente de marketing (2), gerente de inovação (1) e gerente de tendências e estudos avançados em inovação (1).

O instrumento de coleta de dados elegido para este estudo foi a entrevista em profundidade. Assim, a partir de um roteiro semiestruturado, foram realizadas conversas presenciais e remotas (videochamadas), tendo duração de 25 a 30 minutos. O material coletado, após transcrição literal, foi analisado com base na técnica de Análise de Conteúdo. Dessa forma, a análise dos relatos seguiu tópicos explorados no roteiro das entrevistas, tais como: "O que foi percebido de diferente na apresentação da estratégia?"; "Os recursos utilizados na apresentação da estratégia auxiliaram a compreensão da proposta e tomada de decisão?"; "A estratégia definida para o projeto desenvolvido trouxe mais resultados do que outras utilizadas anteriormente?"; "Você consegue perceber o que foi discutido e trabalhado durante o processo de construção da estratégia nos resultados apresentados, após a sua implementação?'; "O processo de construção da estratégia ajudou a compreender melhor o contexto em que atua, bem como o seu públicoalvo e como ele se relaciona com o seu negócio?". 


\section{SULDESIGN CIENTÍFICO 2017}

VIII Suldesign - encontro sul-americano

Como descrito, as informações coletadas através das entrevistas, foram analisadas a partir da técnica de Análise de Conteúdo. Tal abordagem se estabelece em cinco etapas, sendo elas: preparação das informações, unitarização, categorização, descrição e interpretação. A partir do material gerado, procurou-se estabelecer uma compreensão mais aprofundada, através da interpretação de significados extrínsecos aos relatos dos entrevistados (MORAES, 1999).

Desse modo, para alcançar o objetivo deste estudo, chegou-se em três categorias de análise, descritas no Quadro 1:

\begin{tabular}{|c|c|}
\hline $\begin{array}{l}\text { Construção } \\
\text { Da estratégia. }\end{array}$ & $\begin{array}{l}\text { Reunir impressões referentes à metodologia e as dinâmicas } \\
\text { adotadas para a construção da estratégia, bem como } \\
\text { aspectos relacionados à instrumentos utilizados no processo. }\end{array}$ \\
\hline $\begin{array}{l}\text { Compreensão da } \\
\text { Estratégia para } \\
\text { Tomada de decisão. }\end{array}$ & $\begin{array}{l}\text { Identificar percepções relacionadas aos recursos utilizados } \\
\text { na apresentação da proposta para a definição da estratégia. }\end{array}$ \\
\hline $\begin{array}{l}\text { Percepção } \\
\text { Dos resultados. }\end{array}$ & $\begin{array}{l}\text { Reconhecer percepções sobre os resultados alcandos, } \\
\text { considerando a relações com o design estratégico. }\end{array}$ \\
\hline
\end{tabular}

Quadro 1: Categorias de Análise. Fonte: desenvolvido pela autora.

Com a categoria "Construção da Estratégia" buscou-se agrupar percepções relacionadas à metodologia e às dinâmicas executadas para a construção da estratégia. Tal classificação se dividiu em outras duas subcategorias: "Instrumentos de Design", reunindo impressões sobre os instrumentos utilizados no processo, e "Processo de Design", agrupando percepções referentes ao processo em si. A segunda categoria denominada como "Compreensão da Estratégia para Tomada de Decisão" agrupa percepções relacionadas aos recursos utilizados na apresentação da proposta para a definição da estratégia. Por fim, a última categoria "Percepção dos Resultados" engloba aspectos referentes ao alcance de resultados e vantagem competitiva.

A discussão dos resultados analisados (cap. 5) relaciona-se com as reflexões teóricas centrais deste estudo, a fim de atender o objetivo de compreender a percepção das organizações referente ao design estratégico e os resultados atingidos, após implementarem suas estratégias.

\section{Resultados e Discussões}

\section{Construção da estratégia.}

Os entrevistados, ao serem questionados sobre a metodologia e as dinâmicas realizadas para a construção da estratégia, revelaram percepções significativas relacionadas à prática do design estratégico. A fala de um dos entrevistados exemplifica aspectos sobre a abordagem da empresa contratada: " $A$ metodologia adotada foi fundamental para se ter uma visão ampliada do problema e do negócio como um 
todo." Pode-se observar nesta afirmação, a compreensão da natureza exploratória do design, que diante de um determinado problema torna-se capaz de lidar com o conhecimento e a informação com uma visão holística. Para este fim, tal disciplina faz uso de ferramentas que sustentam sua ação processual e permitem alcançar alternativas diferenciadas.

Dessa forma, identificaram-se nos relatos dos entrevistados impressões referentes aos instrumentos de design utilizados na elaboração da estratégia. Alguns relatos dos participantes expõem tais percepções: "As ferramentas auxiliaram a redefinir o problema de forma a torná-lo mais claro para a proposição de soluções"; "É muito mais simples entender um segmento ou perfil de usuário, a partir de sua personificação."; "[As dinâmicas] adotam caráter colaborativo, onde todos contribuem para a melhor solução".

Tais afirmações reforçam a ideia de que a prática do design estratégico se estabelece a partir de instrumentos que buscam facilitar a ação projetual e a indicar direções ao longo do seu processo (COSTA e MOREIRA, 2010). Os projetos de design caracterizam-se pela não linearidade e inconstâncias, sendo um processo aberto, suas abordagens apoiam-se em ferramentas que fomentam a troca entre diferentes atores para a geração de novas soluções. Assim, torna-se um processo participativo, envolvendo pessoas afetadas pelo mesmo problema, desde as etapas de concepção de estratégias até as fases de implantação das soluções propostas. É um ato criativo e colaborativo que acontece com o objetivo de inspirar os atores envolvidos e guiá-los ao longo das fases de projetação (SANDER e STAPPERS, 2008).

Complementando, entende-se que, por atuar no âmbito coletivo, o design estratégico tem a habilidade de ativar o processo criativo nas organizações, catalisando novos conhecimentos. Nesse sentido, pôde-se identificar nas falas dos entrevistados percepções referentes ao seu processo: "[Sim,] o método auxiliou bastante para enxergarmos o negócio e o mercado em que atuamos."; "[Percebi também, que a metodologia] auxiliou na quebra de paradigmas internos da empresa [,permitindo assim, a adoção de soluções mais criativas para se atingir os objetivos.]".

Tais relatos refletem o que Zurlo (2010) descreve sobre a capacidade do design em organizar e tornar compreensível todos os elementos que englobam um determinado contexto. Para o autor, o designer traz para o problema de projeto um olhar crítico sobre os objetivos estabelecidos, buscando compreender as razões que o geraram. Assim, o esforço de interpretar além do que é solicitado, contribui com uma visão mais ampla sob as premissas do projeto.

Outro ponto que converge com o pensamento do autor está relacionado à capacidade do design estratégico em gerar efeito de sentido a todos os indivíduos de um determinado contexto. Sob uma perspectiva processual, que reúne diferentes conhecimentos, sua prática permite a criação de novos pontos de vistas sob modelos mentais existentes. Dessa forma, novos significados são atribuídos aos problemas de projeto, bem como às potenciais soluções destes problemas. De acordo, Celaschi e Franzato (2012) explicam que tal capacidade se constitui através do metaprojeto, permitindo uma reflexão crítica ao decorrer do projeto, gerando o aprofundamento no problema e nos objetivos traçados. 


\section{Compreensão da estratégia para tomada de decisão.}

Buscou-se identificar as impressões dos entrevistados em relação aos recursos utilizados pela empresa contratada para a apresentação da estratégia. Nota-se em alguns relatos que a forma como a proposta foi exposta aos clientes, facilitou a compreensão da estratégia sugerida bem como a tomada de decisão: Os recursos visuais "[e, principalmente, a busca pela apresentação de diferentes propostas] auxiliaram na tomada de decisão."; "[Dessa forma,] a tomada de decisão se tornou mais fácil porque foi possível visualizar o que foi feito e o que pode ser complementado."

Observa-se que as impressões trazidas pelos clientes esclarecem a importância da compreensão da construção da estratégia para a tomada de decisão. Da mesma forma, Zurlo (2010) destaca as capacidades funcionais do design: ver, prever e fazer ver. Para o autor, ao ver o designer exercita sua habilidade de observar e interpretar contextos, permitindo extrair a essência do ambiente analisado para novas oportunidades. Ao prever, através da projetação de cenários futuros, desenvolve sua capacidade criativa, capaz de interpretar e antecipar acontecimentos. Por fim, ao fazer ver o designer pratica a capacidade que sustenta o seu agir estratégico, tornando visível as ideias e os conceitos desenvolvidos, através de imagens, protótipos, referências, dentre outros. Esta última ação, além de tangibilizar a solução proposta, é capaz de facilitar e acelerar o processo de tomada de decisão.

\section{Percepções dos resultados.}

Afim de analisar a percepção dos clientes em relação ao design estratégico, após a implementação das estratégias, buscou-se compreender que resultados os entrevistados atribuem às potencialidades do design.

Pode-se perceber poucas impressões relacionadas a questões monetárias, refletindo a dificuldade das organizações em mensurar ganhos financeiros e vantagens competitivas por meio do design estratégico (ROE, 2013). Contudo, um dos clientes relacionou os resultados financeiros atingidos às potencialidades do design, com esta fala: "Os resultados financeiros aumentaram consideravelmente, algo em torno de 4 a 5 vezes em média do faturamento mensal que tínhamos [,em relação ao ano passado]".

Já os demais entrevistados atribuíram os resultados atingidos à questões comportamentais, tais como: "Mudou a visão interna sobre o nosso próprio negócio."; "Houve uma mudança no comportamento interno [da empresa, promovendo iniciativas de ações que buscam valorizar os nossos clientes e nosso core business].".

Ao descreverem as mudanças comportamentais e de perspectivas sobre os seus negócios, os entrevistados reforçam o que Zurlo (2010) descreve sobre as estratégias orientadas pelo design. Para o autor, o design estratégico ao conduzir o processo de construção da estratégia, gera significados a toda cadeia de valor, fazendo com que os resultados envolvam e motivem diferentes atores, indo além de questões financeiras. No âmbito organizacional, o efeito de sentido torna-se capaz de provocar nos 
colaboradores a motivação para adquirirem novas competências e a contribuírem com iniciativas direcionadas à competitividade e melhora de desempenho das empresas nas quais trabalham.

O Quadro 2 apresenta uma síntese da análise realizada, a qual permitiu compreender e interpretar as impressões dos entrevistados em relação ao design estratégico:

\begin{tabular}{|c|c|c|}
\hline CATEGORIAS & : DESCRIÇÃO & : DETALHAMENTO \\
\hline $\begin{array}{l}\text { Construção } \\
\text { da estratégia. }\end{array}$ & $\begin{array}{l}\text { Metodologia e dinâmicas } \\
\text { adotadas para a construção } \\
\text { da estratégia. }\end{array}$ & $\begin{array}{l}\text { : "As ferramentas auxiliaram a redefinir o problema de forma a } \\
\text { : torná-lo mais claro para a proposição de soluções." } \\
\text { : "I.... trouxe uma imensa experiência de imersão e pensar o negócio." }\end{array}$ \\
\hline $\begin{array}{l}\text { Compreensão da } \\
\text { Estratégia para } \\
\text { Tomada de decisão. }\end{array}$ & $\begin{array}{l}\text { : Recursos utilizados na } \\
: \text { apresentação da proposta } \\
\text { : } \\
\text { estratégia. }\end{array}$ & $\begin{array}{l}\text { : "As apresentações foram elucidativas." } \\
\text { : "Os recursos visuais [...] auxiliaram na tomada de decisão." } \\
\text { : "I...] clareza como as ideias são expostas, como funcionariam, } \\
\text { a quem atinge [...]". }\end{array}$ \\
\hline $\begin{array}{l}\text { Percepção } \\
\text { Dos resultados. }\end{array}$ & $\begin{array}{l}\text { Elementos que } \\
\text { demonstram o alcance } \\
\text { de resultados. }\end{array}$ & $\begin{array}{l}\text { : "l...] nos permitiu solucionar uma série de problemas } \\
\text { que possuíamos }[. . .] " \\
\text { : "[...]" criando um hábito novo no cliente que nos procura." }\end{array}$ \\
\hline
\end{tabular}

Quadro 2: Síntese da Análise. Fonte: desenvolvido pela autora.

Tendo realizado as análises do material coletado, a seção seguinte apresenta as considerações finais sobre o presente estudo.

\section{Conclusões}

Considerando o atual cenário econômico, percebe-se o crescente número de empresas que têm trazido às suas práticas de gestão a perspectiva do design. Contudo, ainda encontram-se dificuldades em compreender e medir os resultados gerados pelo design estratégico como um ativo de alto desempenho e diferenciação. Nesse contexto, o presente artigo buscou refletir sobre a seguinte questão: "Como as organizações atribuem seus resultados à perspectiva do design estratégico?”. Dessa forma, buscou-se analisar a percepção das empresas após implementarem estratégias desenvolvidas por meio do design. Como forma de complementar os conceitos explorados, foram realizadas entrevistas em profundidade com 4 clientes de uma empresa gaúcha de Tecnologia da Informação, que oferece serviços de design estratégico.

A partir da revisão teórica e da análise do material coletado nas entrevistas, percebe-se que a prática do design desperta novas descobertas e percepções durante a sua ação projetual. Foi possível identificar evidências relacionadas ao seu processo, que apontaram para 3 tópicos significativos para este estudo: (a) impressões relacionadas ao processo de construção da estratégia; (b) a importância da compreensão da estratégia para a tomada de decisão; e, (c) aspectos relacionados aos resultados atingidos, após a implementação das estratégias. 
Tais questões permitiram identificar elementos que sustentam o design estratégico como um campo capaz de agregar valor às organizações. Com base na análise realizada, percebe-se a influência de suas ferramentas para a melhor compreensão da estratégia desenvolvida, bem como na facilitação para a tomada de decisão. A mudança comportamental dos indivíduos das organizações investigadas reforça a capacidade do design estratégico em gerar novos sentidos para todos os envolvidos em um determinado contexto, fazendo com que os resultados atingidos englobem diferentes atores. Por fim, a visão sistêmica do design é percebida pelas organizações, na medida em que permite que todos os envolvidos na projetação da estratégia interpretem além do que é estabelecido como objetivo, contribuindo com uma visão mais ampla sob as premissas dos processos de construção de valor.

Porém, observou-se a falta de clareza sobre os ganhos financeiros atingidos pelas organizações, relacionados ao design. De qualquer forma, identifica-se um campo de análise a ser explorado, especialmente no que diz respeito à compreensão das organizações aos ganhos em lucratividade, competitividade e abertura de novos mercados atribuídas ao design estratégico.

Salienta-se que este artigo buscou contribuir com estudos que buscam compreender o potencial do do design como orientador de estratégias organizacionais, ampliando a visão focada no processo de construção da estratégia para uma perspectiva mais ampla. Tal perspectiva considera que a investigação sobre a potencialidade do design nos processos de construção de estratégias apresente elementos que apontem sua importância nos resultados e vantagens competitivas das organizações. Assim, sugere-se para futuras pesquisas diferentes abordagens, em especial quantitativas que possam mensurar aspectos e percepções que não podem ser medidos e interpretados de forma direta. Buscando, assim, compreender o escopo e a complexidade das organizações em relacionarem os ganhos alcançados por meio de design estratégico.

\section{Referências}

CELASCHI, F. Dentro al progetto: appunti di merceologia contemporanea: In: CELASCHI, F.; DESERTI, A. Design e innovazione: strumenti e pratiche per la ricera applicada. Roma: Carocci Editore, 2007, p.15-38.

CROSS, N. Design Thinking: Undestanding how designers think and work. Berg: Nova lorque, 2011.

CROSS, N. Designerly ways of knowing. Springer: London, 2006.

CROSS, N. Expertise in design: an overview. Design Studies, [S.I.], v. 25, n.5, p. 427-441. Sept., 2004.

DESERTI, A. Intorno al progetto: concretizzare l'innovazione. In: CELASCHI, F.; DESERTI, A. Design e innovazione: strumenti e pratiche per la ricerca applicata. Roma: Carocci Editore, 2007, p. 57-61.

DURRANT A. C. el al. Developing a Dialogical Plataform for Disseminating Research Through Design. Constructivist Foundations, 11, 1, 8-21, Nov. 2015

FINDELI, A. Rethinking Design Education for the 21st Century: Theorical, Methodological, and Ethcical Discussion. Design Issues. 17, 1, 5-17, Abril, 2001

FLUSSER, V. O mundo codificado. Por uma Filosofia do design e da comunicação. $1^{\text {a }}$ ed. São Paulo: 
Cosac Naify, 2007.

FRAGA, Eliara. Workshops em design: espaços de aprendizagens e geração de conhecimentos. Dissertação (Mestrado) - Universidade do Vale do Rio dos Sinos - UNISINOS, Programa de Pós-Graduação em Design, 2011.

FRAYLLING, Christopher. Research in Art and Design. London: Royal College of Art, 1993.

FRIEDMAN, K. Theory Construction in design research: criteria, approaches, and methods. Design Studies, 24, 2003, (507-522).

GAVER, W. What should we wxpet from research through design? In:

SIGCHI Conference on humam factores in Computing Systems. ACM, New York, 2012, 937-946.

HEIJDEN, K. V. Planejamento de Cenários. Porto Alegre: Bookman, 2009.

JONAS, W. Research Through Design is more than just a new forma of disseminating design. Constructivist Foundations, 11, 1, 32-36, Nov. 2015

KAHNEMAN, D. Maps of bounded rationality: psychology for behaviral economics. The American Economic Review, v.93, n.5, p.1449-1475, 2003.

KOSKINEN, Ilpo et. al. Design Research Through Practice: From the lab, field and showroom. Waltham: Elsevier, 2012.

MATURANA, H. R., \& VARELLA, F. J. (2001). A árvore de conhecimento: as bases para a compreensão humana. São Paulo: Palas Athena.

MERONI, A. Strategic design: where are we now? Reflection around the foundations of a recent discipline. Strategic Design Research Journal, v. 1, n. 1, p. 31-38, 1 dez. 2008.

POLANYI, M. The Tacit Dimension.London: Routledge and Kegan Paul, 1966.

REYES, P. Projeto por cenários: o território em foco. Porto Alegre: Sulina, 2015. 268p.

SCHÖN, D. Educando o profissional reflexivo: um novo design para o ensino e a aprendizagem. Porto Alegre: Artmed Editora, 2000.

SIMON, Herbert A.; As ciências do articial / The Sciences of the artificials. M.I.T, 1981.

ZIMMERMANN, J. STOLTERMAN, E. FORLIZZI, J. An Analysis and Critique of Research through Design: towards a formalization of research approach. Denmark, 2010. 